\title{
Impact of Postmigration Living Difficulties on the Mental Health of Afghan Migrants Residing in Istanbul
}

\author{
Qais Alemi, ${ }^{1}$ Carl Stempel, ${ }^{2}$ Kelly Baek, ${ }^{1}$ Lisa Lares, ${ }^{1}$ Patricia Villa, ${ }^{1}$ \\ Didem Danis, ${ }^{3}$ and Susanne Montgomery ${ }^{4}$ \\ ${ }^{1}$ Department of Social Work and Social Ecology, School of Behavioral Health, Loma Linda University, Loma Linda, CA 92354, USA \\ ${ }^{2}$ Department of Sociology and Social Services, California State University, East Bay, Oakland, CA 94607, USA \\ ${ }^{3}$ Department of Sociology, Galatasaray University, 34349 Istanbul, Turkey \\ ${ }^{4}$ Department of Social Work \& Social Ecology, Behavioral Health Institute, Loma Linda University, Redlands, CA 92373, USA
}

Correspondence should be addressed to Qais Alemi; qalemi@llu.edu

Received 25 April 2016; Accepted 28 August 2016

Academic Editor: Sally Guttmacher

Copyright (C) 2016 Qais Alemi et al. This is an open access article distributed under the Creative Commons Attribution License, which permits unrestricted use, distribution, and reproduction in any medium, provided the original work is properly cited.

\begin{abstract}
Background. The sociopolitical situation in Afghanistan continually pushes Afghans to seek safety and better socioeconomic prospects in neighboring and foreign countries. In this paper we examine the mental health of Afghan migrants residing in Istanbul, Turkey, an understudied population at high risk of psychopathology. Methods. We surveyed 158 Afghan migrants to assess psychological distress using a culturally grounded measure of mental health, the Afghan Symptom Checklist [ASCL], and used hierarchical regression analysis to examine the impact of postmigration living difficulties (PMLDs) on mental health. Results. We found that depressive, somatoform, anxiety-like symptoms occurred often, as did a number of culturally salient idioms of distress. Regression analyses showed that while socioeconomic variables and poor physical health status significantly predicted psychological distress, PMLDs exerted the strongest negative effect. The most pressing PMLDs for Afghans in Turkey are poverty, unemployment, lack of treatment for health problems, fears of being deported and related legal challenges, and family-related stressors. Conclusion. Our results point to the importance of the critical need to create culturally sensitive interventions to remediate high levels of psychological distress by addressing related PMLD stressors in a highly vulnerable Afghan migrant population residing in Turkey.
\end{abstract}

\section{Introduction}

The volatile civil war in Syria and conflict and economic instability in Iraq, Afghanistan, and North Africa have led to unprecedented population movements from the Middle East to the European Union (EU). An estimated 1.26 million new asylum claims were made in EU nations at the end of 2015 [1]. Among these close to 64,000 new claims were made by asylum seekers either directly from Afghanistan due to social and economic disadvantages [2] or from Afghan refugees who previously resided in Iran and Pakistan, and are now leaving these countries after governments have shifted policies about Afghan refugees in their territories. For example, Iranian authorities announced that they will not renew work permits for Afghans because the current embargo has significantly affected their economy, while authorities in
Pakistan stipulated that (undocumented) Afghans may be subject to immediate deportations [3]. Therefore, conditions in these countries have made it difficult for Afghans to enter the labor market, in addition to instilling fears of being sent back to Afghanistan where the country's immediate future remains uncertain leading to increased migration to Turkey.

As part of this population movement, Turkey has become a major transit country for Afghans seeking to reach EU countries [4] and while some Afghans seek to permanently resettle in Turkey with over 90,000 asylum claims by mid2016 [5], most migrants are deemed illegal. Indeed, Turkish asylum policies promote asylum rights only to refugees from Europe, and settlement laws grant legal status only to people of Turkish descent and culture [6]. Most EU countries' policies of closed borders have not stopped this migration and have instead resulted in an illegal underclass that is highly 
exploited [7] and lives in inhumane conditions due to poverty [8]. While this is true for all immigrant groups, the plight of Afghan migrants tends to be worse than that of Syrian refugees, a population viewed by the Turkish government as having a legitimate need for (temporary) protection but still facing restrictions from accessing the formal labor market, health services, and education for their children [9].

A recent systematic review of quantitative and qualitative studies on Afghan refugees and asylum seekers that resettled in western nations reveals high rates of depression and posttraumatic stress disorder (PTSD) associated with premigration traumas and postresettlement stressors to include economic strain, status and social support loss, and limited host country social integration [10]. Studies of other nationalities show that common psychiatric disorders in refugees and asylum seekers are intensified by host country detention [11], fears of being deported [12], worry about family back home/family separation $[13,14]$, and long asylum processes [15]. Asylum processes that delay residence permits have been shown to limit socioeconomic integration [16] and deter family reunification [17] factors that have recently been shown to play a protective role in psychological health among asylum seekers in Australia [18] and the Netherlands [19]. While these studies provide new insights into the plight of refugees and asylum seekers, the validity of a few of these studies $[11,12,14,17,18]$ is tempered by the cross-sectional study design including small and nonrepresentative sample sizes and in some cases the use of measures validated in research with nonrefugee populations.

The current study aims to build on prior studies of Afghans in exile by examining the mental health of Afghan migrants residing in Istanbul, Turkey. We refer to Afghans in this study as "migrants," due to their inability to obtain an official refugee status in Turkey.

Specifically, we examine the severity of psychological distress using a culturally grounded measure of mental health developed in Afghanistan, the Afghan Symptom Checklist or ASCL [20]. We also examined the extent to which sociodemographic factors, self-reported physical health status, and postmigration living difficulties contribute to their psychological distress. We hypothesized that sociodemographic variables of conceptual relevance and poor physical health status would significantly predict psychological distress and that postmigration living difficulties would have the greatest (negative) impact on the mental health of respondents.

\section{Methods}

2.1. Sample, Setting, and Procedures. Inclusion criteria for this cross-sectional study were being of Afghan ancestry, 18 years of age or older, and residing in Istanbul, Turkey, regardless of legal classification (transit migrant, refugee, or asylum seeker). Power analysis using $G^{*}$ Power software, version 3.1 [21], estimated that a sample size of 172 participants was required based on obtaining a moderate effect size of $f^{2}=$ .15 , type I error of $\alpha=.05$, and power of $(1-\beta)=.80$. The Afghan first author and an Afghan research assistant collected data over a 10-day period in late September 2015 within Istanbul's Zeytinburnu district, a resettlement hub for Afghans and other immigrants. Recruitment involved a combination of street-intercept, convenience, and snowball sampling methods. Before administering surveys, an IRBapproved information sheet was presented to participants, which we used to obtain verbal consent. Of note, we successfully argued to not require a signature for consent, as previous studies found that this discouraged potential participants from responding since it reminded them of past confrontations with authorities [22], thus undermining trust and rapport.

\subsection{Instrumentation}

2.2.1. Sociodemographic Information (Control Variables). We elicited data on age, gender, marital status, years in Turkey, educational attainment, and employment status. A proxy for income was assessed by asking participants whether they could comfortably pay bills every month with their current household income ("yes/no"), a method previously used with Afghan refugees [23]. We assessed social support using another proxy measure asking "Do you have family present in Turkey (“yes/no”)?”

2.2.2. Physical Health (Control Variable). We assessed physical health status using items from the physical health component of the Short-Form/SF-8 [24] (mean score of four items). This includes a measure of self-rated health, the level of bodily pain one is experiencing, and two items on how much physical health limits daily work and physical activities. Scores range from 0 to 18 with higher scores on the health index denoting greater physical health. The health index demonstrated adequate internal consistency in this sample (Cronbach's $\alpha=.772$ ).

2.2.3. Postmigration Living Difficulties (Independent Variable). We used the Postmigration Living Difficulties (PMLD) checklist [25] for measuring the severity of postmigration problems commonly encountered by asylum seekers within the past 12 months. Items relate to immigration matters, employment-related challenges, access to various types of health services, and isolation/loneliness/separation. Responses are rated on a five-point Likert-type scale ranging from "0" ("no problem at all") to " 4 " ("a very serious problem") with total scores ranging from 0 to 96 . A principal components analysis (PCA) procedure with varimax rotation and Kaiser normalization yielded five components with all but one item ("worries about family back home") loading at .550 or higher on a component. Table 3 shows the five subscales that were created (PMLDs 1-5) and their respective Cronbach's alphas (ranging from .719 to .891). PCAs were also conducted on each subscale. Each PCA found only one component with an eigenvalue of 1.0 or higher and that component explained the range from $53.9 \%$ to $73.8 \%$ of the variance.

\subsubsection{General Psychological Distress (Outcome Variable).} We used the Afghan Symptom Checklist (ASCL) [20] for measuring the frequency of distress symptoms. Originally developed and validated in Afghanistan, the ASCL consists 
of 23 distress items, including some traditional items known to western psychiatry relating to depressive symptoms (e.g., crying, insomnia, and social withdrawal), as well as some items aligned with Afghan society such as indigenous idioms and indicators relating to ruminative sadness ("jigar khun"/sadness resulting from a painful experience, "thinking too much"), somatic distress (e.g., "fishar e bala"/internal agitation), and stress induced reactivity (e.g., "asabi"/stressful irritability). Each question is asked for the previous two weeks. Scores range from 23 to 115 derived from response choices ranging from "1" ("never") to "5" ("everyday"). The ASCL has been used in research with Afghan refugees in southern California [22] in which Afghans reported comparably lower levels of psychological distress $(\mathrm{M}=41.7, \mathrm{SD}=$ $15.55)$ than men $(\mathrm{M}=50.54, \mathrm{SD}=12.10)$ and women $(\mathrm{M}=$ 68.21, SD = 16.70) in Afghanistan [20]. The ASCL demonstrated excellent reliability in this sample (Cronbach's $\alpha=$ .942).

2.3. Data Analysis. SPSS, version 23.0, was used for all data analysis. Both categorical and continuous variables were subjected to bivariate tests to examine associations with ASCL scores using one-way ANOVAs, independent samples $t$-tests, and Pearson's correlations where appropriate. For scales with less than $10 \%$ missing data we used the mean substitution method [26] to replace missing values for continuous variables. Data was screened to assure linearity and normality and to test for multicollinearity as similar constructs were used as predictor variables across various steps in our regression analysis but no data transformations or exclusion of constructs was warranted. Hierarchical regression analysis was used to develop a predictive model of psychological distress. In Model 1 demographic covariates of conceptual relevance were controlled; physical health status was subsequently added in Model 2, and the PMLD (full scale) was added in Model 3. Additionally, in order to better understand which PMLD items were most salient for this sample, we removed the PMLD long scale and instead incorporated the five PMLD subscales identified through our PCA in Model 4. In Model 5 we entered only the PMLD subscales that were significantly associated $(p<.05)$ with psychological distress in Model 4.

\section{Results}

3.1. Sociodemographic Characteristics. Table 1 displays the sociodemographic characteristics of our participants. Most of the 158 Afghan participants were male ( $n=130,83.3 \%$ ); ranged in age from 18 to 57 years with a mean age of 25.67 $(\mathrm{SD}=7.87)$; reported an average length of residence in Turkey of 2.55 ( $\mathrm{SD}=3.31$ ) years; were not having family present in Turkey $(n=101,64.7 \%)$; were unemployed $(n=118,78.7 \%)$; and had unstable incomes $(n=117,75.5 \%)$. Perceived health status ranged from 0 to 18 with a mean rating of $10.49(\mathrm{SD}=$ 4.21), and PMLD scores ranged from 3 to 96 with a mean of $48.65(\mathrm{SD}=21.05)$.

Bivariate analyses conducted for multivariate model building purposes exploring the relationship between SES and other variables of interest and psychological distress indicated that unemployment $(t(148)=4.712, p<.001)$, lower income $(t(153)=5.321, p<.001)$, lower physical health/ scores on the health index $(r=-.524, p<.001)$, and PMLDs $(r=.671, p<.001)$ were significantly associated with higher psychological distress symptoms. These significantly related items were then retained for the multivariate model analyses.

3.2. Severity of Distress Symptoms (Outcome Variable). ASCL scores ranged from 24 to 115 with a mean of 60.17 (SD = 20.50). Table 2 shows reported distress symptoms occurring at least once per week. Some of the most frequently reported symptoms include "feeling sad," "trouble concentrating," "thinking too much," "difficulty sleeping," and becoming "jigar khun" (a form of sadness resulting from a deeply painful experience).

3.3. Extent of Postmigration Living Difficulties. Table 3 displays each of the PMLD subscales and the frequency with which items were rated as "serious" to "a very serious problem." Five of nine items within the first subscale, "conditions of extreme precarity" (e.g., poverty, deportation fears, and being unable to return home in an emergency), were rated by from serious to very serious by over $50 \%$ of the sample whereas "asylum-related difficulties" (PMLD 2) were less often noted as a serious concern. At least half of the participants endorsed all three items relating to "employment-related problems" (PMLD 3) from serious to very serious. "Access to medical and social services" (PMLD 4) was problems for many as shown in the fourth subscale, and in the "marginalization and family-related stressors" (PMLD 5) subscale family-related items were pressing for more respondents.

\subsection{Impact of Postmigration Living Difficulties on Mental} Health. Table 4 shows the results of a series of regressions to test the influence of the four sociodemographic variables and perceived physical health index that correlated in the bivariate analyses with the ASCL at $p<.10$. In addition we explored the association of the PMLD (full scales and subscales) with the ASCL. In Model 1 we entered the control variables of years residing in Turkey, family members in Turkey (proxy for social support), employment, and income. This model explained $22.6 \%$ of the variance with income and employment being significantly (and negatively) associated with distress levels. Years in Turkey and having family in Turkey were not significantly associated with distress.

The physical health index (Model 2) and the full PMLD index (Model 3) were added in subsequent models. Model 2 shows that, as expected, the health index is negatively associated with psychological distress $(\beta=-.453, p<.001)$. The health index explains additional $17.4 \%\left(\Delta R^{2}=.174\right)$ of the variance (beyond the base model) and has a standardized beta more than double that of either income or employment. Model 3 shows that adding the full PMLD to the base model explains additional $16.4 \%$, slightly less than the health index. This suggests that the health index influences psychological distress slightly more than the PMLD checklist. 
TABLE 1: Descriptive statistics: continuous and categorical variables and dependent variables (psychological distress/ASCL) measured at bivariate level $(N=158)$.

\begin{tabular}{|c|c|c|c|c|c|}
\hline \multirow{2}{*}{ Variables } & \multirow{2}{*}{$n(\%)$} & \multicolumn{2}{|c|}{ Psychological distress/ASCL } & \multirow{2}{*}{ Statistic $(r, t$, or $F)$} & \multirow{2}{*}{ Sig. $p$ value } \\
\hline & & $\mathrm{M}$ & $\mathrm{SD}$ & & \\
\hline Age: $\mathrm{M}=25.67, \mathrm{SD}=7.87$ & - & - & - & $r=-.112$ & .600 \\
\hline \multicolumn{6}{|l|}{ Gender $^{\dagger}$} \\
\hline Female & $26(16.7)$ & 62.62 & 21.26 & \multirow{2}{*}{$t=.67$} & \multirow{2}{*}{.507} \\
\hline Male & $130(83.3)$ & 59.67 & 20.54 & & \\
\hline \multicolumn{6}{|l|}{ Marital status ${ }^{\ddagger}$} \\
\hline Divorced, separated, widowed & $7(4.5)$ & 67.17 & 25.32 & \multirow{3}{*}{$F=1.324$} & \multirow{3}{*}{.269} \\
\hline Never married & $85(54.8)$ & 61.31 & 18.95 & & \\
\hline Married & $63(40.6)$ & 56.97 & 21.18 & & \\
\hline \multicolumn{6}{|l|}{ Education $^{\phi \phi}$} \\
\hline Less than high school & $60(38.9)$ & 63.66 & 18.64 & \multirow{3}{*}{$F=2.043$} & \multirow{3}{*}{.110} \\
\hline High school & $68(44.2)$ & 58.18 & 21.56 & & \\
\hline College and beyond & $26(16.9)$ & 55.17 & 19.62 & & \\
\hline \multicolumn{6}{|l|}{ Family in Turkey ${ }^{\dagger}$} \\
\hline Yes & $55(35.3)$ & 56.27 & 17.23 & \multirow{2}{*}{$t=1.710$} & \multirow{2}{*}{.089} \\
\hline No & $101(64.7)$ & 62.14 & 22.04 & & \\
\hline \multicolumn{6}{|l|}{ Legal status } \\
\hline Asylum seeker & $52(32.9)$ & 63.43 & 18.18 & \multirow{2}{*}{$t=-1.404$} & \multirow{2}{*}{.162} \\
\hline Refugee & $106(67.1)$ & 58.57 & 21.44 & & \\
\hline Years in Turkey: $\mathrm{M}=2.55, \mathrm{SD}=3.31$ & - & - & - & $r=-.135$ & .092 \\
\hline \multicolumn{6}{|l|}{ Employment status ${ }^{\phi}$} \\
\hline Unemployed & $118(78.7)$ & 63.91 & 19.85 & \multirow{2}{*}{$t=4.712$} & \multirow{2}{*}{.000} \\
\hline Employed & $32(21.3)$ & 45.72 & 17.46 & & \\
\hline \multicolumn{6}{|l|}{ Income $e^{\ddagger}$} \\
\hline Comfortable & $38(24.5)$ & 45.66 & 17.37 & \multirow{2}{*}{$t=5.397$} & \multirow{2}{*}{.000} \\
\hline Not comfortable & $117(75.5)$ & 64.84 & 19.53 & & \\
\hline Physical health: $\mathrm{M}=10.49, \mathrm{SD}=4.21$ & - & - & - & $r=-.524$ & .000 \\
\hline PMLDs: $\mathrm{M}=48.65, \mathrm{SD}=22.70$ & - & - & - & $r=.577$ & .000 \\
\hline
\end{tabular}

Note. ${ }^{\dagger} N=156,{ }^{\ddagger} N=155,{ }^{\phi \phi} N=154$, and ${ }^{\phi} N=150$.

However, we get a different picture in Model 4, which replaces the full PMLD with the five PMLD subscales. The five subscales explain much more variance $\left(30.8 \%\right.$ or $\left.\Delta R^{2}=.308\right)$ than either the health index (Model 2) or the full PMLD (Model 3). Four of the five subscales are significantly related to psychological distress, with PMLD 1 (conditions of extreme precarity) most strongly associated with distress $(\beta=.463$, $p<.001$ ) and PMLD 3 (employment-related problems) not significantly related to distress at $p<.05$. Note that PMLD 4 (access to medical and social services) is significantly but negatively related to distress. These results run counter to expectations and are additionally surprising because its bivariate correlation with distress is positive $(r=.380, p<$ $.001)$. Thus, controlling for the other subscales reverses the direction of the relationship between PMLD 4 and distress. When included in the full PMLD index, PMLD 4 items act to weaken the PMLDs influence on distress.

To verify this we ran a regression (not shown) using a scale consisting of 20 PMLD items (not including items from PMLD 4), and it has nearly the same change in $R^{2}$ as Model 4. In comparing Model 5 to Model 2, we see that adding the four PMLD subscales to the model with demographic controls and health status explains additional $14.5 \%$ of the variance ( $R_{\text {Adjusted }}^{2}$ increases from $40.0 \%$ in Model 2 to $54.5 \%$ in Model 5). It shows that the health index remains significant at $p<.05$ as do PMLDs 1, 2, and 5. Of these, PMLD 1 is most strongly associated with distress, with a standardized beta $(\beta=.436)$ more than double any of the other variables.

\section{Discussion}

The sociopolitical situation in Afghanistan indicates no end sight for the exodus of Afghans in search of safety and better socioeconomic prospects in neighboring and foreign countries. Afghans residing in Turkey are an understudied population who, as observed here, are at high risk of psychopathology. The results of this study show that distress symptoms occur at rates higher than previously reported in the US [23] and mirror those of research conducted in Afghanistan [20]. Of note, items indicative of depression, anxiety, and somatoform symptoms occurred often, as did a number of culturally salient idioms of distress, information 
TABLE 2: Frequency (from most to least) of reported distress symptoms occurring $\geq 1$ /week $(N=158)$.

\begin{tabular}{|c|c|}
\hline & $n(\%)$ \\
\hline Feeling sad & $139(88.0)$ \\
\hline Trouble concentrating ${ }^{* * *}$ & $135(87.1)$ \\
\hline Thinking too much* & $134(85.4)$ \\
\hline Difficulty falling asleep & $133(84.2)$ \\
\hline $\begin{array}{l}\text { Becoming jigar khun (reaction to a painful } \\
\text { experience) }\end{array}$ & $132(83.5)$ \\
\hline Asabi (highly stressed) & $125(79.1)$ \\
\hline Feeling irritable & $125(79.1)$ \\
\hline Felt hopeless & $125(79.1)$ \\
\hline Loss of appetite & $120(75.9)$ \\
\hline Headaches* ${ }^{*}$ & $119(75.8)$ \\
\hline Intrusive, unwanted memories ${ }^{\dagger}$ & $113(71.5)$ \\
\hline Trouble remembering things* & $112(71.3)$ \\
\hline $\begin{array}{l}\text { Difficulty meeting responsibilities at home or at } \\
\text { work }^{* *}\end{array}$ & $109(69.9)$ \\
\hline Nightmares & $\begin{array}{c}108 \\
(68.4)\end{array}$ \\
\hline Easily startled & $107(67.7)$ \\
\hline Fishar e bala (internal agitation)* & $98(62.4)$ \\
\hline Crying & $93(58.9)$ \\
\hline Fishar e payin (low energy) ${ }^{*}$ & $77(49.0)$ \\
\hline Quarreling with a family member & $68(43.3)$ \\
\hline Quarreling with a neighbor & $56(35.4)$ \\
\hline Beating or hurt oneself** & $50(32.1)$ \\
\hline Feeling socially withdrawn or isolated & $40(25.5)$ \\
\hline Beating one's children* & $37(23.6)$ \\
\hline
\end{tabular}

Note. ${ }^{*} N=157 ;{ }^{* *} N=156 ;{ }^{* * *} N=155$.

that could be used to guide the development of much needed culturally salient interventions [27].

The degree of distress reported here was found to be associated with the rampant levels of unemployment and inadequate income (Model 1), which aligns with prior studies of Afghans and other nationalities showing similar associations $[28,29]$. Much of the influence of employment and income is mediated by both health status and postmigration living difficulties, as indicated by the low and nonsignificant beta for income and employment in the full regression (Model 5). This raises a question of causal processes that a larger sample panel study might illuminate. Additionally, the predictive power of the [poor] physical health status variable on ASCL scores was demonstrated, even net of postmigration difficulties. This points to the importance of addressing both the health needs and living difficulties of this population and justifies the inclusion of physical health variables in future research that utilizes the PMLD checklist.

Our findings only partially confirm our first research hypothesis given that null associations were observed between ASCL scores and other key variables, possibly due to low representation of respondents within variable subcategories. For example, ASCL scores did not vary by length of residence in Turkey, as was found, for example, among Sri Lankan refugees in Canada [30]. This may reflect the precarious conditions and status of even longtime Afghan residents in Turkey and raises questions of whether over time conditions might improve for Afghans in Turkey, at least in the current political climate with continuing influx of refugees into Turkey.

The PMLD checklist in its full form as tested here confirmed our second research hypothesis, but we found the PMLDs' explanatory power greatly increased by dividing it into subscales or removing the four items in PMLD 4 ("access to medical and social services"). Using five subscales generated by Principal Components Analysis also improved our understanding of which living difficulties most influence distress levels for this population. The strongest influence on distress is PMLD 1 ("conditions of extreme precarity"), which includes fears of being sent home, poverty, loneliness, and poor access to medical care that reflect the conditions of this community of Afghan migrants most of whom are without legal status, unemployed, and unable to enter the formal labor market. It is likely that many are forced to accept low wages in poor job conditions within the informal economy, as previously documented in Syrian refugees [9]. Indeed, the negative correlation of PMLD 4 controlling for the other PMLD subscales likely reflects the extreme precarity of this population. That is, worries about access to dentistry, counseling services, and welfare, although important, are not central concerns of individuals in highly precarious situations.

In addition to the influence of conditions of extreme precarity, we found that subscales related to asylum challenges (e.g., conflict with immigration officials) and marginalization (e.g., communication difficulties) and family-related stressors (e.g., worry about family in Afghanistan) contributed to the high distress levels. These findings parallel the stressors documented with Iraqi [13] and Sudanese asylum seekers [14] and suggest that well-being and adjustment for Afghans in Turkey may indeed be hindered by basic unmet needs impeding basic human survival, including resources such as personal health, paid employment, and social support [31]. Thus we contend that, alongside the need to remediate distress symptoms, a first response should be to improve basic living conditions of Afghans in Turkey. While no solid evidence exists on specific interventions for improving the mental health of Afghans and other migrant groups [32], evidence points towards addressing the aforementioned psychosocial stressors alongside remediating traumatic symptoms, which may optimally facilitate functional improvements [33]. Studies of asylum seekers in Australia [18] and in the Netherlands [19] emphasize that improving health may require interventions that advocate for tangible necessities such as access to gainful employment, work rights, family reunification, and legal residency.

Our finding that the items in PMLD 4 substantially suppressed the influence of the full PMLD points to the importance of conducting analyses that reflect the diversity of difficulties captured in this scale. That Cronbach's $\alpha$ for the full PMLD is .930 demonstrates the limitations of this reliability measure without also considering factor structure. 
TABLE 3: Frequency of respondents endorsing living difficulties as "serious" to "very serious" $(N=158)$ and PMLD subscales.

\begin{tabular}{|c|c|c|}
\hline & $\begin{array}{c}\text { Serious/very serious } \\
n(\%)\end{array}$ & Subscales $^{\mathrm{a}}$ \\
\hline Unable to return home in emergency & $91(57.6)$ & \multirow{9}{*}{$\begin{array}{c}\text { PMLD } 1 \\
\text { (conditions of extreme precarity) } \\
\alpha=.891 \\
\text { PCA: } 53.9 \% \text { of variance }\end{array}$} \\
\hline Fears of being sent home & $90(57.0)$ & \\
\hline Worries about not getting treatment for health problems & $85(53.8)$ & \\
\hline Poor access to emergency medical care & $70(44.3)$ & \\
\hline Poor access to long-term medical care & $67(42.4)$ & \\
\hline Poverty & $102(64.6)$ & \\
\hline Loneliness and boredom & $83(52.5)$ & \\
\hline Isolation & $63(39.9)$ & \\
\hline Poor access to the foods you like & $75(47.5)$ & \\
\hline Being in detention & $35(22.3)$ & \multirow{4}{*}{$\begin{array}{c}\text { PMLD 2 } \\
\text { (asylum difficulties) } \\
\alpha=.809 \\
\text { PCA: } 63.1 \% \text { of variance }\end{array}$} \\
\hline Interviews by immigration & $41(25.9)$ & \\
\hline Delays in processing your application & $41(25.9)$ & \\
\hline Conflict with immigration officials & $42(26.6)$ & \\
\hline No permission to work & $87(55.1)$ & \multirow{3}{*}{$\begin{array}{c}\text { PMLD 3 } \\
\text { (employment-related problems) } \\
\alpha=.825 \\
\text { PCA: } 73.8 \% \text { of variance } \\
\end{array}$} \\
\hline Not being able to find work & $93(58.9)$ & \\
\hline Bad job conditions & $79(50.0)$ & \\
\hline Poor access to dentistry care & $70(44.3)$ & \multirow{4}{*}{$\begin{array}{c}\text { PMLD } 4 \\
\text { (access to medical and social services) } \\
\alpha=.854 \\
\text { PCA: } 69.4 \% \text { of variance }\end{array}$} \\
\hline Poor access to counseling services & $62(39.2)$ & \\
\hline Little government help with welfare & $59(37.3)$ & \\
\hline Little help with welfare from charities & $52(32.9)$ & \\
\hline Communication difficulties & $65(44.1)$ & \multirow{4}{*}{$\begin{array}{c}\text { PMLD } 5 \text { (marginalization and } \\
\text { family-related stressors) } \\
\alpha=.719 \\
\text { PCA: } 54.9 \% \text { of variance }\end{array}$} \\
\hline Discrimination & $27(17.1)$ & \\
\hline Separation from family & $92(58.2)$ & \\
\hline Worries about family back home & $110(69.6)$ & \\
\hline
\end{tabular}

Note. ${ }^{*} N=157 ;{ }^{* *} N=156 ; N=155 .{ }^{\text {a }}$ PCAs of each subscale had one component with an eigenvalue of 1.0 or higher. We report the percentage of variance explained by that one component.

TABLE 4: Hierarchical regression analyses showing associations with psychological distress (DV).

\begin{tabular}{|c|c|c|c|c|c|}
\hline & \multicolumn{5}{|c|}{ Psychological distress/ASCL } \\
\hline & Model 1 & Model 2 & Model 3 & Model 4 & Model 5 \\
\hline & $\beta$ & $\beta$ & $\beta$ & $\beta$ & $\beta$ \\
\hline Years of residence in Turkey & .062 & .069 & .032 & .040 & .057 \\
\hline Family in Turkey & -.093 & -.088 & -.088 & -.088 & -.100 \\
\hline Employment & $-.271^{* * *}$ & $-.186^{*}$ & $-.183^{*}$ & -.070 & -.059 \\
\hline Income & $-.352^{* * *}$ & $-.221^{* *}$ & $-.156^{*}$ & -.071 & -.066 \\
\hline Physical health & & $-.453^{* * *}$ & & & $-.194^{*}$ \\
\hline PMLD (full) & & & $.456^{* * *}$ & & \\
\hline PMLD 1 & & & & $.463^{* * *}$ & $.436^{* * *}$ \\
\hline PMLD 2 & & & & $.183^{*}$ & $.151^{*}$ \\
\hline PMLD 3 & & & & .087 & \\
\hline PMLD 4 & & & & $-.181^{*}$ & -.153 \\
\hline PMLD 5 & & & & $.200^{*}$ & $.175^{*}$ \\
\hline$R^{2}$ & .247 & .421 & .411 & .555 & .575 \\
\hline Adjusted $R^{2}$ & $.226^{* * *}$ & $.400^{* * *}$ & $.389^{* * *}$ & $.524^{* * *}$ & $.545^{* * *}$ \\
\hline$\Delta R^{2}$ & & $.174^{* * *}$ & $.164^{* * *}$ & $.308^{* * *}$ & $.328^{* * *}$ \\
\hline$F$-statistic & 11.663 & 20.498 & 18.863 & 17.881 & 19.367 \\
\hline
\end{tabular}

Note. ${ }^{*} p<.05,{ }^{* *} p<.01$, and ${ }^{* * *} p<.001$. 
4.1. Strengths and Limitations. A major strength of this study is that we used a culturally grounded measure of mental health to assess distress levels, which is critical considering the lack of relevant instruments commonly used in research with refugees [34]. While our study points to significant needs of this hard to access population several limitations should also be noted. First, the cross-sectional design does not allow for causal inferences. Also, the small sample size obtained through convenience sampling limits generalizability especially with respect to the limited number of female participants, though this imbalance is somewhat representative of the actual migration trends which favors males. Moreover, to limit respondent burden, we constrained our measures to currently experienced psychological distress, thus not allowing us to tease out current versus premigration and transit-related traumatic experiences. For brevity sake we also did not assess potentially important constructs such as acculturation to Turkish culture and used a single-item measure to assess social support instead of a validated scale. Any of these might fall under salient factors described in a recent qualitative study of US-based Afghan refugees [35] and could have served as important control variables here as these likely also had an impact on our participants mental health.

4.2. Conclusion. This study further contributes to our understanding of the mental health of Afghan migrants, an understudied and highly vulnerable group, largely deemed illegal whose status in Turkey may propagate an ongoing cycle of poverty, poor health, and psychopathology. Throughout the data collection process the vast majority of participants displayed great curiosity about the potential use of the information. Nearly all expressed the hope that it would be used to inform positive responses to their needs by local authorities. While there is clear need with respect to physical and mental health, most primarily spoke of the pressing need to remediate other tangible postresettlement stressors such as the need to work and provide for their families. Also, as mostly single, younger men are the ones setting out to find better lives, many have lost important sources of social support. Perhaps intervention efforts could begin by building on the experience and social capital of those who have lived longer and are more established in the informal Afghan communities in Istanbul. Even at nominal remuneration this would provide meaningful engagement for those who would share their experience, while at the same time helping those who are new to this environment. While modest, such an effort could serve as a first and somewhat realistic step toward helping improving the dire situations many Afghan migrants endure and help prevent frustrations from becoming increasingly adversarial.

\section{Competing Interests}

The authors declare that they have no competing interests.

\section{Acknowledgments}

The authors thank the participants in this study for their time and useful insights. They also thank Mr. Najib Nooristani for his assistance with collecting data. Dr. Qais Alemi would like to gratefully acknowledge the support provided by a seed grant from the Behavioral Health Institute at Loma Linda University. Also, Dr. Didem Danis would like to express her gratitude for the support provided by Galatasaray University Scientific Research Division (BAP Grant no. 16.502.001)

\section{References}

[1] Eurostat, Asylum Statistics, 2016, http://ec.europa.eu/eurostat/ statistics-explained/index.php/Asylum_statistics.

[2] C. Panter-Brick, M. Eggerman, A. Mojadidi, and T. W. McDade, "Social stressors, mental health, and physiological stress in an urban elite of young Afghans in Kabul," American Journal of Human Biology, vol. 20, no. 6, pp. 627-641, 2008.

[3] International Organization for Migration, "Transition, crisis and mobility in Afghanistan: rhetoric and reality," https://www. iom.int/files/live/sites/iom/files/Country/docs/Transition-Crisis -and-Mobility-in-Afghanistan-2014.pdf.

[4] A. Icduygu, "Transit migration in Turkey: trends, patterns, and issues," Research Report 4, European University Institute, Florence, Italy, 2005.

[5] United Nations High Commissioner for Refugees, "UNHCR Turkey's monthy statistics as of January 2016," 2016, http://www .unhcr.org/turkey/uploads/root/eng(58).pdf.

[6] A. İçduygu, Syrian Refugees in Turkey: The Long Road Ahead, Migration Policy Institute, Washington, DC, USA, 2015.

[7] M. G. Carta, M. Bernal, M. C. Hardoy et al., "Migration and mental health in Europe (the state of the mental health in europe working group: appendix I)," Clinical Practice and Epidemiology in Mental Health, vol. 1, no. 1, article 13, 2005.

[8] T. Seibert, Afghan refugees leave Iran for Turkey, 2013, http:// www.thenational.ae/news/world/europe/afghan-refugees-leave -iran-for-turkey.

[9] K. Kirişci, Syrian Refugees and Turkey's Challenges: Going Beyond Hospitality, Brookings Institution, Washington, DC, USA, 2014.

[10] Q. Alemi, S. James, R. Cruz, V. Zepeda, and M. Racadio, "Psychological distress in Afghan refugees: a mixed-method systematic review," Journal of Immigrant and Minority Health, vol. 16, no. 6, pp. 1247-1261, 2014.

[11] M. Ichikawa, S. Nakahara, and S. Wakai, "Effect of postmigration detention on mental health among Afghan asylum seekers in Japan," Australian and New Zealand Journal of Psychiatry, vol. 40, no. 4, pp. 341-346, 2006.

[12] M. Toar, K. K. O’Brien, and T. Fahey, "Comparison of selfreported health \& healthcare utilisation between asylum seekers and refugees: an observational study," BMC Public Health, vol. 9, no. 1, article 214, 2009.

[13] C. J. Laban, H. B. P. E. Gernaat, I. H. Komproe, I. Van Der Tweel, and J. T. V. M. De Jong, "Postmigration living problems and common psychiatric disorders in Iraqi asylum seekers in the Netherlands," The Journal of Nervous and Mental Disease, vol. 193, no. 12, pp. 825-832, 2005.

[14] R. Schweitzer, F. Melville, Z. Steel, and P. Lacherez, "Trauma, post-migration living difficulties, and social support as predictors of psychological adjustment in resettled Sudanese refugees," Australian and New Zealand Journal of Psychiatry, vol. 40, no. 2, pp. 179-187, 2006.

[15] C. J. Laban, I. H. Komproe, H. B. P. E. Gernaat, and J. T. V. M. de Jong, "The impact of a long asylum procedure on quality of 
life, disability and physical health in Iraqi asylum seekers in the Netherlands," Social Psychiatry and Psychiatric Epidemiology, vol. 43, no. 7, pp. 507-515, 2008.

[16] L. Bakker, J. Dagevos, and G. Engbersen, “The importance of resources and security in the socio-economic integration of refugees. A study on the impact of length of stay in asylum accommodation and residence status on socio-economic integration for the four largest refugee groups in the Netherlands," Journal of International Migration and Integration, vol. 15, no. 3, pp. 431-448, 2014.

[17] K. Carswell, P. Blackburn, and C. Barker, "The relationship between trauma, post-migration problems and the psychological well-being of refugees and asylum seekers," International Journal of Social Psychiatry, vol. 57, no. 2, pp. 107-119, 2011.

[18] D. C. Hocking, G. A. Kennedy, and S. Sundram, "Mental disorders in asylum seekers: the role of the refugee determination process and employment," The Journal of Nervous and Mental Disease, vol. 203, no. 1, pp. 28-32, 2015.

[19] M. Lamkaddem, M.-L. Essink-Bot, W. Devillé, A. Gerritsen, and K. Stronks, "Health changes of refugees from Afghanistan, Iran and Somalia: the role of residence status and experienced living difficulties in the resettlement process," The European Journal of Public Health, vol. 25, no. 6, pp. 917-922, 2015.

[20] K. E. Miller, P. Omidian, A. S. Quraishy et al., "The Afghan Symptom Checklist: a culturally grounded approach to mental health assessment in a conflict zone," American Journal of Orthopsychiatry, vol. 76, no. 4, pp. 423-433, 2006.

[21] F. Faul, E. Erdfelder, A.-G. Lang, and A. Buchner, "G* Power 3: a flexible statistical power analysis program for the social, behavioral, and biomedical sciences," Behavior Research Methods, vol. 39, no. 2, pp. 175-191, 2007.

[22] A. A. M. Gerritsen, I. Bramsen, W. Devillé, L. H. M. van Willigen, J. E. Hovens, and H. M. van der Ploeg, "Use of health care services by Afghan, Iranian, and Somali refugees and asylum seekers living in The Netherlands," The European Journal of Public Health, vol. 16, no. 4, pp. 394-399, 2006.

[23] Q. Alemi, S. James, H. Siddiq, and S. Montgomery, "Correlates and predictors of psychological distress among Afghan refugees in San Diego County," International Journal of Culture and Mental Health, vol. 8, no. 3, pp. 274-288, 2015.

[24] J. E. Ware, M. Kosinski, J. E. Dewey, and B. Gandek, SF-8 Health Survey Manual-How to Score and Interpret Single-Item Health Measures: A Manual for Users of the Sf-8 Health Survey, Quality Metric Incorporated, Lincoln, RI, USA, 2001.

[25] D. Silove, I. Sinnerbrink, A. Field, V. Manicavasagar, and Z. Steel, "Anxiety, depression and PTSD in asylum-seekers: associations with pre-migration trauma and post-migration stressors," The British Journal of Psychiatry, vol. 170, pp. 351-357, 1997.

[26] J. Cohen, P. Cohen, S. G. West, and L. S. Aiken, Applied Multiple Regression/Correlation Analysis for the Behavioral Sciences, Routledge, Mahwah, NJ, USA, 2013.

[27] B. A. Kohrt, A. Rasmussen, B. N. Kaiser et al., "Cultural concepts of distress and psychiatric disorders: literature review and research recommendations for global mental health epidemiology," International Journal of Epidemiology, vol. 43, no. 2, Article ID dyt227, pp. 365-406, 2014.

[28] S. S. Lecerof, M. Stafström, R. Westerling, and P.-O. Östergren, "Does social capital protect mental health among migrants in Sweden?" Health Promotion International, vol. 31, no. 3, pp. 644-652, 2016.

[29] F. Lindencrona, S. Ekblad, and E. Hauff, "Mental health of recently resettled refugees from the Middle East in Sweden: the impact of pre-resettlement trauma, resettlement stress and capacity to handle stress," Social Psychiatry and Psychiatric Epidemiology, vol. 43, no. 2, pp. 121-131, 2008.

[30] M. Beiser, A. M. Goodwill, P. Albanese, K. McShane, and P. Kanthasamy, "Predictors of the integration of Sri Lankan Tamil refugees in Canada: pre-migration adversity, mental health, personal attributes, and post-migration experience," International Journal of Migration, Health and Social Care, vol. 11, no. 1, pp. 29-44, 2015.

[31] D. Ryan, B. Dooley, and C. Benson, “Theoretical perspectives on post-migration adaptation and psychological well-being among refugees: towards a resource-based model," Journal of Refugee Studies, vol. 21, no. 1, pp. 1-18, 2008.

[32] N. Crumlish and K. O'Rourke, "A systematic review of treatments for post-traumatic stress disorder among refugees and asylum-seekers," The Journal of Nervous and Mental Disease, vol. 198, no. 4, pp. 237-251, 2010.

[33] A. Nickerson, R. A. Bryant, D. Silove, and Z. Steel, "A critical review of psychological treatments of posttraumatic stress disorder in refugees," Clinical Psychology Review, vol. 31, no. 3, pp. 399-417, 2011.

[34] M. Hollifield, T. D. Warner, N. Lian et al., "Measuring trauma and health status in refugees: a critical review," The Journal of the American Medical Association, vol. 288, no. 5, pp. 611-621, 2002.

[35] Q. Alemi, S. James, and S. Montgomery, "Contextualizing Afghan refugee views of depression through narratives of trauma, resettlement stress, and coping," Transcultural Psychiatry, vol. 53, no. 5, pp. 630-653, 2016. 


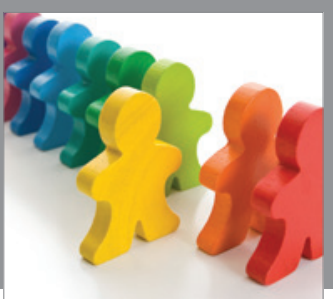

Autism

Research and Treatment
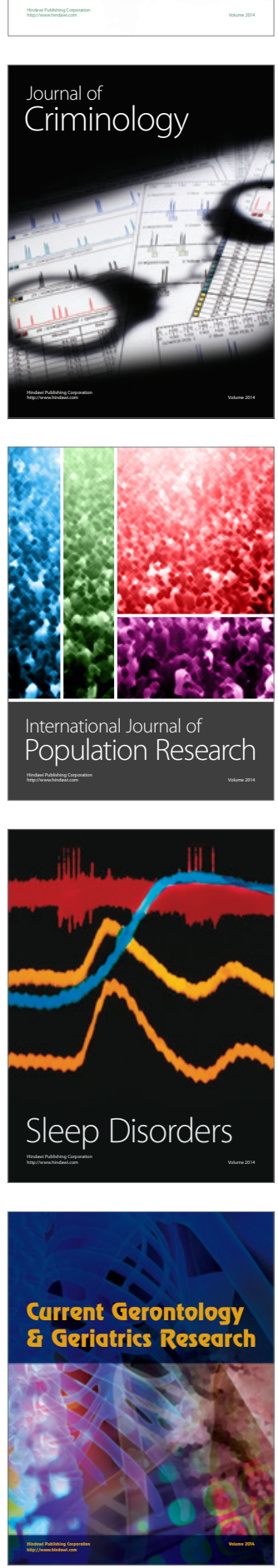

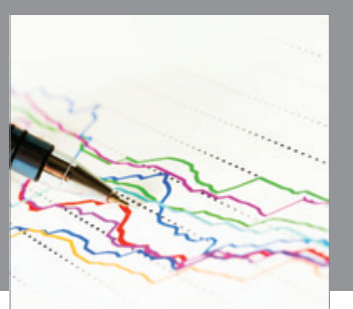

Economics

Research International
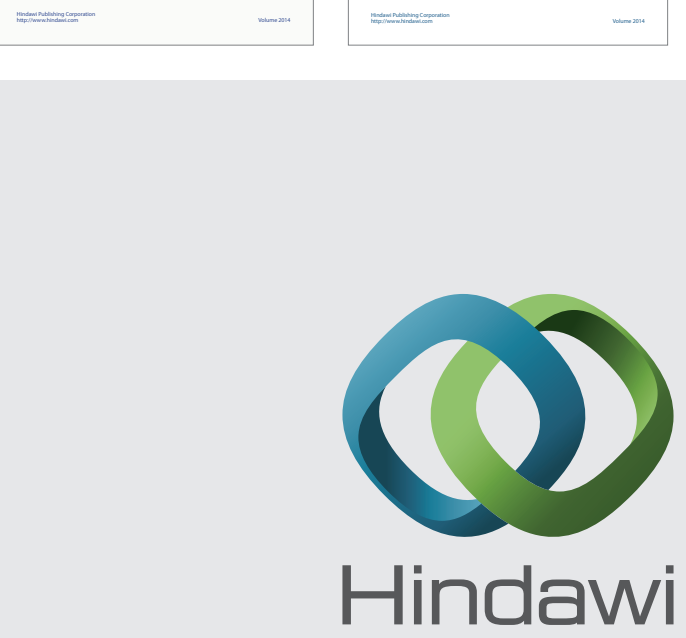

Submit your manuscripts at

http://www.hindawi.com
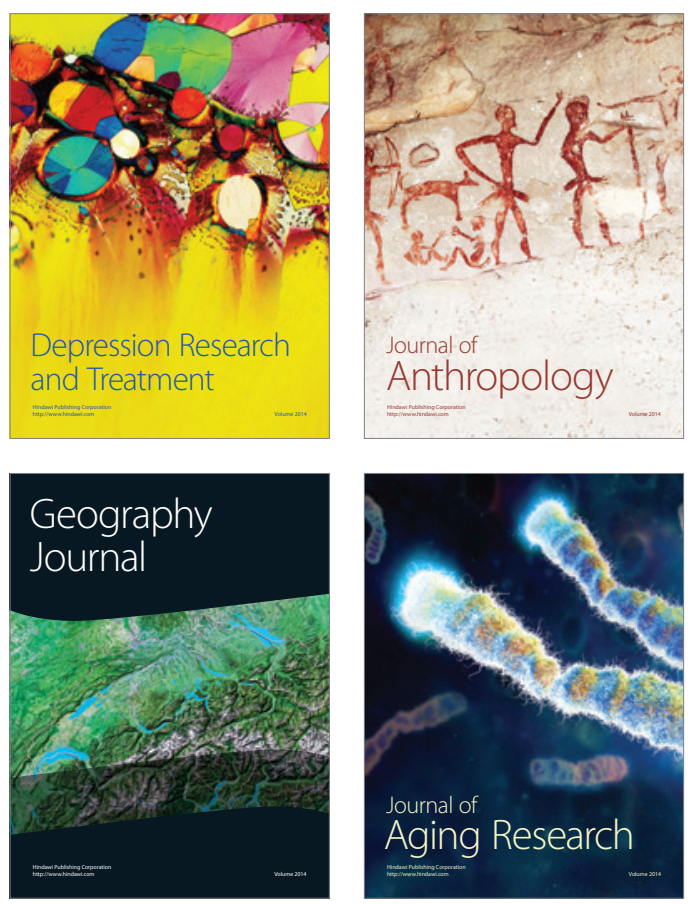
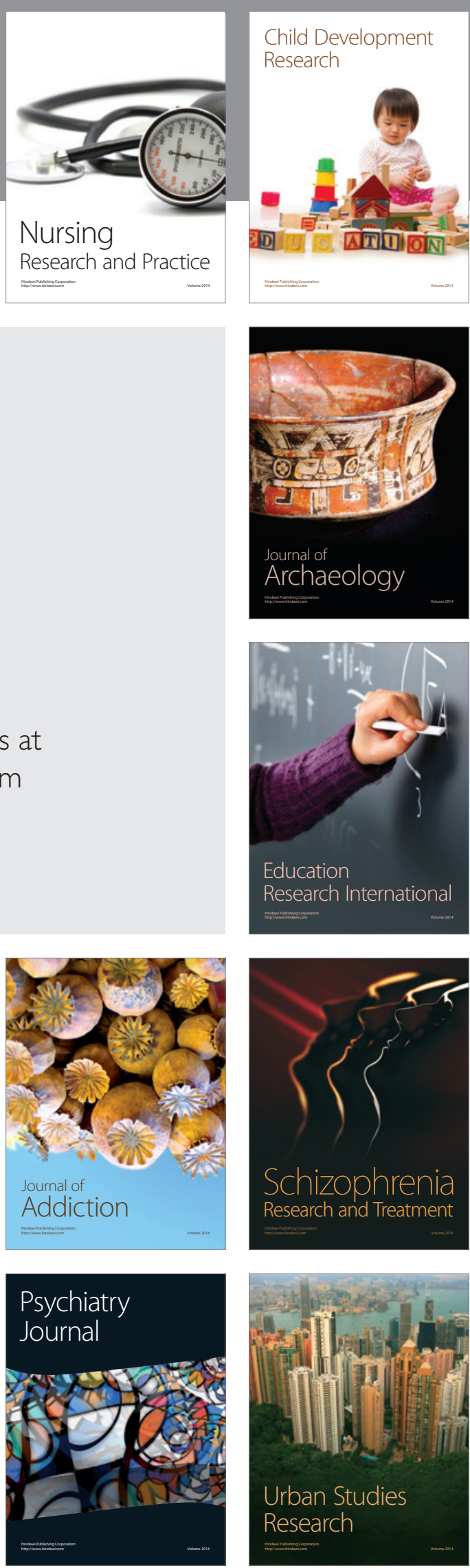